\title{
An Assessment of Supply Chain Flexibility in the Bottling Water Industry in Ghana
}

\author{
Evans Kyeremeh
}

\begin{abstract}
Companies nowadays face complex, continuously changing and uncertain environment through accelerating technological changes, global competition, innovation, rise in customer demands and expectations, expansion of market and other factors has necessitated firms to adopt supply chain flexibility in their operations to cope with the uncertainties in the business environment to meet the fluctuations in demand. Flexibility in supply chain management creates an opportunity for the firms to improve its operational scope in order to achieve competitive advantage. Adoption of the flexibility strategies helps companies to increase their market share and growth and stay in competitive business. Some of the flexibility measures include product development cycle time, product variety and customer requirements disparity. The study seeks to determine the supply chain flexibility drivers and the extent to which these drivers have influence on the supply chain performance in the bottling water industry in Ghana. Questionnaires were employed as a tool to collect the primary data from the field and the secondary data were collected from Internet and articles. Both qualitative and quantitative methods were adopted. The study was limited to the bottling water industry in the Kumasi Metropolis due to its geographical location and availability of market. The findings indicated that existing products must be modified to attract customers. The study recommends among others that there should be product modification, avoiding shortage of raw materials and customer complaints should be handled tactically in order to attract customers and increase sales.

Index Terms-Customer Order Lead-Time, Customer Requirement Disparity, Customer Satisfaction, Product Life Cycle, Product Variety and Supply Chain Management.
\end{abstract}

\section{INTRODUCTION}

In most modern economies, supply chain management is one of the important mechanisms companies employ to achieve competitive advantage. The competition among firms needs strategies and prudent measures to boost productivity so as to maximize profitability. Supply chain management is about managing the linkages, which support the movement of products from a firm's supplier to a firm's customers. The Institute for supply chain management defines supply chain as "the design and management of seamless, value-added processes across organizational boundaries to meet the real need of the end customer" [1]. Council of Supply Chain
Management Professionals (CSCMP) emphasize that supply chain management encompasses the planning, and management of all activities involved in sourcing, procurement, conversion and logistics management [2]. In essence, supply chain management integrates supply and demand management within and across companies. The business environment is full of uncertainties, so there is the need for the firms to adapt something new, and different strategies that is peculiar to that particular firm in order to deal with the demand expectations of the customers. Flexibility is described as an adaptive response to the uncertainties in the environment. [3], state that flexibility is a mechanism that enables firms to cope with this increasing uncertainty because it facilitates a quick response, which is strategically important as an order-winning criterion.

According to [4], flexibility is a reflection of the ability of a system to change or react with little penalty in time, effort, cost or performance.

Flexibility in supply chain management creates an opportunity for the firms to improve its operational scope in order to achieve competitive advantage, which also brings success to the organization. However, proliferations of product varieties have necessitated the essence of being flexible in business. There is the need for the whole business network to perform creditably by adhering to measures and strategies that would help the organizations to achieve its stated goals and objectives but not individual functions that hinders business prosperity. [5], maintained that manufacturing flexibility is one of the major competitive weapons for manufacturers in today's increasingly turbulent market. Flexibility in supply chain may well represent a potential source to improve the company efficiency and may be a significant measure of supply chain performance [6]. This shows that supply chain flexibility is essential in firm's operations to be responsive to customer needs, decrease operation lead- times and adjust swiftly to unforeseen activities. In order for the firms to be operated effectively, there is the need for them to be flexible so that they can reduce production cost, be competitive, and increase their market share, profitability and growth.

The bottling water industry in Ghana specifically in the Kumasi Metropolis has become highly lucrative due to its 
high patronage by consumers. The industry is experiencing continuous increase in number and has become competitive as they strive for market shares and business growth. Though these companies are performing well in the market, they are facing challenges and some of these are high cost of raw materials for production, increases in tariffs, leading to high cost of production, changes in customer behaviour and expectations, production lead-times and unforeseen events such as the current electricity load scheduling and acute water shortages in the Metropolis having heavy toll on the industry. Due to these challenges, most of the companies are not performing well and cannot achieve the desired market growth, profitability and enjoy competitive advantage. In order to retain market share and high growth there is the need for firms to adopt high flexibility in their operations so that customer satisfaction level can be achieved. The study seeks to examine the level of supply chain dimensions in the bottling water industry and how these dimensions affect their production. Also, this research is to determine the supply chain flexibility drivers and the extent to which these drivers have influence over the supply chain performance.

The main objective of the study is to examine the effect of supply chain flexibility on the performance of bottling water industries in the Kumasi Metropolis. The specific objective of the study is to assess the relationship between supply chain flexibility drivers and dimensions in the bottling water industry

\section{SUPPLY CHAIN MANAGEMENT}

There is no single accepted definition of supply chain because of its multi-functionality. A number of scholars have defined it from many different angles. [2], define supply chain to consist of all parties involved, directly or indirectly, in fulfilling a customer request. According to them, the supply chain includes the manufacturer and suppliers, but also transporters, warehouses, retailers, and even customers themselves. Supply chain management is about managing the linkages, which support the movement of products from a firm's supplier to a firm's customers. The Institute for supply chain management defines supply chain as "the design and management of seamless, value-added processes across organizational boundaries to meet the real need of the end customer" [1]. Council of Supply Chain Management Professionals (CSCMP) emphasize that supply chain management encompasses the planning, and management of all activities involved in sourcing, procurement, conversion and logistics management. In essence, supply chain management integrates supply and demand management within and across companies [2]. From the above definitions, supply chain management can be seen as a network of interconnected businesses, overseeing of materials, information, and finances, effective, efficient, reduction of inventory, and cost effective.

\section{SUPPLY CHAIN FLEXIBILITY}

Flexibility is the organization's ability to change or react to environmental uncertainty and to meet the increasing variety of customer expectations without excessive costs, time and organizational disruptions or performance losses. The market is volatile, complex and turbulent and because of this, there is the need for high speed and low cost supply chains that have essential drivers for the organizations. This globalization creates opportunities for managers to conduct business beyond the organization's territories. The major characteristic features of the present business environment are; high demand expectations of customers, customization of products, quality of products, favourable and short lead times and product life cycle. To react efficiently to the above-mentioned characteristics in order to enjoy competitive advantage, firms should be adaptive and flexible to the market uncertainties. The changing market demand, differing supplier lead-time, product quality and information delay are sources of uncertainty that create a need for building 'flexible' supply chains. In dealing with these uncertainties in the global market there is the need for comprehensive supply chain flexibility approach by the organizations to have competitive edge over other firms. Many authors have argued that, flexibility has been proven to be a crucial tool to increase the competitiveness of the organizations in volatile market [7].

According to [8] flexibility is a complex and multidimensional concept. This means it has been very difficult to define flexibility satisfactorily. Although several authors have proposed different definition of flexibility, no cohesive concept is widely accepted, and there still exists many unanswered questions about flexibility, [9]. Flexibility may also be defined as the ability of a system to change or react with little penalty in time, effort, cost or performance (Upton, 1994). Flexibility is the ready capability to adapt to new, different, or changing requirements. [1], quoted Sun Tzu a Chinese Philosopher's views of flexibility stated that "Every minute ahead of the enemy is an advantage". This stressed that a flexible organization operates with short lead times, is responsive to special customer requests and can adjust rapidly to unexpected events.

\section{CONCEPTS OF SUPPLY CHAIN FLEXIBILITY}

According [10], flexibility in supply chain can be described using three distinctive components which are general characteristics of flexible supply chains since it is not described how these components influence the functional operations in the supply chain. Adaptable: Adjust the supply chain's design to meet structural shifts in markets, modify supply network strategies, products and technologies. Alignment: Create incentives along the partners within the 
supply chain for better overall performance. Agility: The ability of a supply chain to respond to short-term changes in demand or supply quickly and handle external disruptions smoothly.

Supply chain flexibility is a multi-dimensional and very necessary to the key success of the company. [11] provided an in-depth classification of flexibility based on different aspects such as hierarchical aspects (flexibility at shop, plant or company level), functional aspects (flexibility in operations, marketing, logistics), strategic aspects (centred on the strategic relevance of flexibility), measurement aspects (focused on global flexibility measures versus context specific ones), object of change (flexibility of product mix, volume) and time horizon aspects (long term versus short term flexibility).

According to [12], supply chain flexibility can be identifying from six components, namely:

Operations system flexibility, which deals with how to configure operations to react to the emerging customer trend. Market flexibility is the ability to mass customize, build close relationships by designing and modifying products. Information systems flexibility is the ability of the firm to build information system appropriately as it responds to changing customer demand. Logistics flexibility is how to receive and deliver products cost effectively. Supply flexibility is the ability to adapt the supply chain according to the supply of product and customer demand and Organizational flexibility deals with marketing of labour force skills to the customer needs and market requirements.

\section{DIMENSIONS OF SUPPLY CHAIN FLEXIBILITY}

Due to the complex nature of supply chain flexibility concept several authors have proposed different dimensions. Since the definitions of flexibility are not standard and widely accepted, there are overlaps between flexibility dimensions and how each author use and name these dimensions. The necessity of the flexibility dimensions depends on the specific environment in which they are being utilized. This means being flexible in an area does not mean that it would work in all environments. According to [12], flexibility dimensions can be viewed from six areas; operation system flexibility, logistics flexibility, market flexibility, supply flexibility, organizational flexibility and information systems flexibility. These dimensions were refined to five by [12] and these are operational systems flexibility, logistics processes flexibility, supply network flexibility, organizational design flexibility, information systems flexibility. Although each author could use different dimensions of supply chain but it is necessary that these dimensions should relate to the features and functions of the supply chain. Considering integration and customer-oriented perspective, three dimensions would be used in this study; product flexibility, delivery flexibility, and information system flexibility.

Product flexibility is the amount of responsiveness for any future change in a product design including new product and derivatives of existing products. [13], models a firm manufacturing product which optimizes the capacity levels for dedicated resources and is flexible resource that can manufacture all products. The 'resource aggregation' risk of product flexibility is where a capacity-disruption could halt the production of both products. Product prices are outside to the model.

Delivery flexibility is the ability of the supply chain to deliver different types of products to the customers with a wide range of volume at a reasonable cost and time. According to [1], fast and reliable delivery requires the reduction of order cycle time and the elimination of variability. In an organization, anything that increases the time or variability of any portion of the order cycle threatens the firm's ability to deliver on time. However, in correct order entry, late supplier delivery, machine breakdown, transportation delay or wrong routing reduces delivery performance and drives costs up [1]. Customers want delivery of goods on time, at the right place and at the right quantity in the right condition so as to satisfy their needs.

Information system flexibility is the ability of the supply chain information systems whether internal or external to share the required information and support-changing requirement of the business with respect to the changing customer's demand [14]. In managing supply chain, there is the need to use other approaches to integrate suppliers, manufacturers, distributors, wholesalers, retailers and customers in order to function effectively. According to [12], the ability of the firm to realign information systems with the changing information needs generate responds to changing customer demand. The Internet reduces the costs of information acquisition, allowing customers to compile product specifications and compare prices.

\section{SUPPLY CHAIN FLEXIBILITY DRIVERS}

Flexibility is largely determined by the operating (internal) and environment (external) characteristics of a supply chain [15]. These determinants are called supply chain flexibility drivers. [16], pointed out that more volatile markets, short product life cycle (PLC) and more sophisticated buyers have contributed to flexibility's emergence as a new strategic imperative.

The Length of Product Life Cycle (PLC): Product life cycle is how long a product stays in the market before its disappearance due to the introduction of new product or time product spends before entering into a market. The production system, product designing and suppliers have to be integrated so that the product life cycle would not be too long. There 
should be a correlation between these factors so that the product life cycle would not affect the product on the market.

Product Variety $(P V)$ : Product variety is concerned with the number of variety of products produced at a particular time or season by the organization. Variations in the delivery and product development functions must be flexible so that customers would require the products. If there is a large product variety, it means small quantity of each product would be needed making delivering of one type of product in the truck and often be uneconomical.

Customer Requirement Disparity (CRD): Customer requirement disparity is defined as the differences in the speed and service levels required by different customers. There is the need for delivery flexibility because of the disparity in customer requirements. In responding to diverging customer requirements it is essential to employ different kinds of transportation to reduce cost on delivering of goods. Customer requirement should be segmented to avoid conflict.

\section{EFFECTS OF SUPPLY CHAIN FLEXIBILITY PERFORMANCE}

Flexibility is one of the core dimensions of supply chain performance that has ability to strengthen the firm's efficiency. Flexibility performance is the linkage that assesses the

Overall potentials of the firm's operation. [6], conducted the empirical study on the relationships between different dimensions of the supply chain flexibility and overall firm's performance. The studies prove that flexibility is related to all measures of business performance and more than that, it is highly related to market share and its growth. [14], emphasize that flexibility has direct effects on performance (financial net profit, sales growth; and non-financial - lead time and customer satisfaction). What is significant here is that each of the supply chain flexibility is related to at least one measure of total firm performance.

[17], used the term supply chain instead of manufacturing because being that strategy is not the only component of manufacturing strategy but also of marketing. Supply chain flexibility is used instead of manufacturing flexibility. The supply chain extends beyond the company's internal flexibility [12].

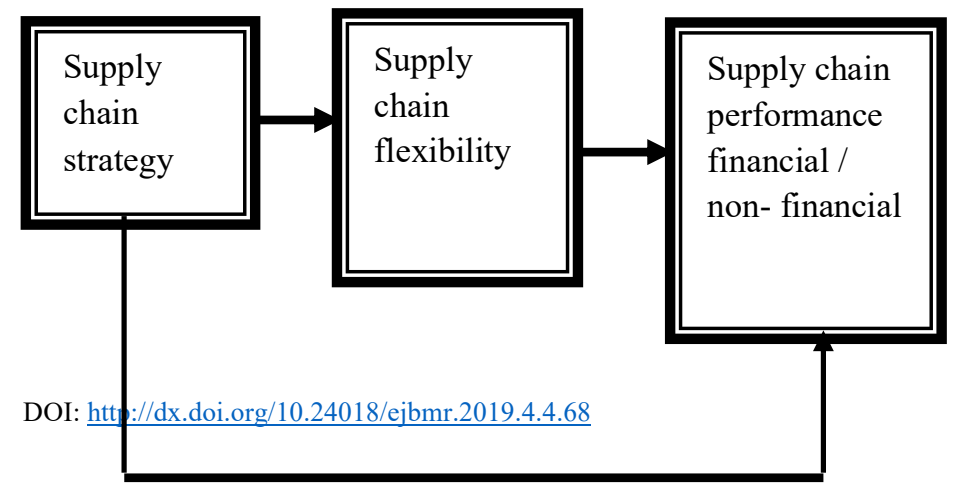

Fig. 1. The Conceptual Basic Model

\section{METHOD}

Research design according to [18] is defined as a blueprint which enables a researcher to structure research questions or problems to produce valid, objective and replicable answers and general empirical evidence. The researcher employed questionnaire as a tool to collect data from the field. Both qualitative and quantitative methods of research were adopted. Qualitative requires content analysis of the data collected which covered the research objectives. The researcher adopted a case study approach for the study. For the study, three (3) bottling water companies were selected to represent the case companies for the research; Voltic Ghana Limited (producers of Voltic Mineral Water), Everpure Ghana Limited (producers of Everpure Drinking Water) and SBC Beverages Ghana Limited (Bottler of Pepsi, and producers of AquaSplash Drinking Water). Though there are many bottling water companies on the market, these three companies were selected on the basis that they control the major proportion of the market share and also their products are widely distributed nationwide. Quantitative analysis requires computer software, SPSS to carry out the activity. Exploratory and descriptive research methods were adopted. Both primary and secondary sources of data were applied to get accurate information from respondents. A maximum of thirty operations and other supply chain managers and fifteen staff members from the three bottling water manufacturing industries in the Kumasi Metropolis were selected for the study. The reason why the sample size is small was that not all the managers in these firms could provide information required for the study. In all the total of forty (45) respondents were selected. [18], state that questionnaire is best selected to collect data needed to test the hypothesis. Questionnaire allows contact with otherwise inaccessible contacts; it costs less time and money to reach the sample population; a questionnaire is perceived as more anonymous and it also allows respondents time to think about the questions. To determine the right and efficient data collection for the research, questionnaire was adopted as the method of collecting data. Questionnaires make analyses of data collected easily and effectively. In developing the questionnaire the researcher divided it into four main sections: demographic data, supply chain flexibility dimensions, 
drivers of supply chain flexibility, and supply chain performance. The respondents were asked to rate the extent of the overall ability of their system with respect to supply chain flexibility dimensions. Using a five-point Likert-scale the types could be rated from (1) "very low" to (5) "very high". The third section deals with the supply chain flexibility drivers. The respondents were asked to rank the supply chain flexibility drivers from Low/Small/Short [ 1 ], Medium [ 2 ] to High/Large/Long[ 3 ]. The last part, supply chain performance, respondents were asked to measured using a five-point Likert-scale. The respondents were required to indicate how different performance measures compared with those of their major competitors with a scale (1) being "very low" to (5) being "very high". The Statistical Package for Social Sciences (SPSS) was adopted to analyze the data collected to facilitate accuracy.

\section{CORRELATION COEFFICIENT}

This is a quantitative instrument to measure strength of linear relationship between two variables say $x_{\text {and }} y$. There are two types of measures: Pearson product-moment measure and Spearman coefficient.

\begin{tabular}{|c|c|c|c|c|c|c|c|c|}
\hline $\begin{array}{l}\text { Product } \\
\text { Flexibility }\end{array}$ & $\mathrm{N}$ & 1 & 2 & 3 & 4 & 5 & Mean & SD \\
\hline $\begin{array}{l}\text { Existing products } \\
\text { modification }\end{array}$ & $\begin{array}{l}3 \\
7\end{array}$ & $\begin{array}{l}0 \\
0\end{array}$ & $\begin{array}{l}2 \\
5.4\end{array}$ & $\begin{array}{l}24 \\
64.9\end{array}$ & $\begin{array}{l}11 \\
29.7\end{array}$ & $\begin{array}{l}0 \\
0\end{array}$ & 3.24 & $\begin{array}{l}0.54 \\
8\end{array}$ \\
\hline $\begin{array}{l}\text { Managing setup } \\
\text { cost and time for } \\
\text { machines }\end{array}$ & $\begin{array}{l}3 \\
7\end{array}$ & $\begin{array}{l}0 \\
0\end{array}$ & $\begin{array}{l}5 \\
13.5\end{array}$ & $\begin{array}{l}18 \\
48.6\end{array}$ & $\begin{array}{l}10 \\
27.0\end{array}$ & $\begin{array}{l}4 \\
10.8\end{array}$ & 3.35 & $\begin{array}{l}0.85 \\
7\end{array}$ \\
\hline $\begin{array}{l}\text { Alternative route } \\
\text { to produce }\end{array}$ & $\begin{array}{l}3 \\
7\end{array}$ & $\begin{array}{l}2 \\
5.4\end{array}$ & $\begin{array}{l}8 \\
21.6\end{array}$ & $\begin{array}{l}17 \\
45.9\end{array}$ & $\begin{array}{l}10 \\
27.0\end{array}$ & $\begin{array}{l}0 \\
0\end{array}$ & 2.95 & $\begin{array}{l}0.84 \\
8\end{array}$ \\
\hline
\end{tabular}

Pearson product-moment measure Correlation Coefficient.

This is used for quantitative data measured on interval or ratio scale. It is defined by

$$
r=\frac{\operatorname{cov}(x, y)}{\delta_{X} \delta_{Y}}=\frac{S S_{x y}}{\sqrt{S S_{x x} S S_{y y}}}
$$

i. $y_{\mathrm{i}}$ is the response variable we wish to estimate or predict

$\mathbf{x}_{\mathrm{i} 1}, \mathbf{x}_{\mathbf{i} 2}, \ldots \mathbf{x}_{\mathrm{ik}}$

$$
\begin{aligned}
S S_{x x}= & \sum_{i=1}^{n}\left(x_{i}-\bar{x}\right)\left(y_{1}-\bar{y}\right) \\
& =\sum_{i=1}^{n} x_{i} y_{i}-\frac{1}{n}\left(\sum_{i=1}^{n} x_{i}\right)\left(\sum_{i=1}^{n} y_{i}\right)
\end{aligned}
$$

$$
\begin{aligned}
& S S_{x x}=\sum_{i=1}^{n}\left(x_{i}-\bar{x}\right)^{2}=\sum_{i=1}^{n} x_{i}^{2}-\frac{1}{n}\left(\sum_{i=1}^{n} x_{1}\right)^{2} \\
& S S_{y y}=\sum_{i=1}^{n}\left(y_{i}-\bar{y}\right)^{2}=\sum_{i}^{n} y_{i}^{2}-\frac{1}{n}\left(\sum_{i=1}^{n} y_{i}\right)^{2}
\end{aligned}
$$

A formulation of the information matrix which will be useful when discussing model fitting and assessment of fit is $\hat{I}(\hat{\beta})=$ $X^{\prime} V X$ where $\mathrm{X}$ is an $n$ by $k+1$ matrix containing the data for each subject, and $\mathrm{V}$ is an $\mathrm{n}$ by $\mathrm{n}$ diagonal matrix with general element $\hat{\pi}_{i}\left(1-\hat{\pi}_{i}\right)$. That is, the matrix $\mathrm{X}$ is

$$
X=\left[\begin{array}{cccc}
1 & x_{11} & \cdots & x_{1 k} \\
1 & x_{21} & \cdots & x_{2 k} \\
\vdots & \vdots & \cdots & \vdots \\
1 & x_{n 1} & \cdots & x_{n k}
\end{array}\right]
$$

\section{RESULTS AND DISCUSSIONS}

\section{A. PRODUCT FLEXIBILITY}

Below is shown the responds of the distribution on the product flexibility by the respondents.

\section{TABLE I: FREQUENCY DISTRIBUTION OF PRODUCT FLEXIBILITY.}

Keys: Very Low $=1$, Low $=2$, Normal $=3$, High $=4$, Very High $=5$

The data collected on the table below depicts that majority of the respondents' responded normal to the modification of the existing features of their products indicating high as shown by the mean value of 3.24. However, few of the respondents indicated low for the modification of products with nonresponsive to very low and very high. The characteristics that distinguish from one another are quality, product designs, packaging, portability, etc. These distinguishing features make the products attractive to the customers who patronized the products and it even lure new customers. Product flexibility can be improved to meet market standards acceptable to the consumers and has allowed industries to expand their operations so that the market share would be increased.

On the other hand, managing setup cost and time for machines was high as indicated by the mean of 3.35 on the table. Meanwhile few respondents indicated low with nonresponsive to very low. The setup cost and time for the machines should be managed effectively and efficiently to avoid breakdowns so that production can be smoothly running in order to decrease setup cost and optimized profit. 
Finally, based on the data collected, the respondents attended to the alternative route to produce products as depicted by the mean 2.95 though it was not high but normal. On the contrary, there were low respondents rated very low to alternative route to produce product. This shows that the manufacturing industries have different ways for production even during the time of massive electricity load shedding these companies still managed to produce products to serve its customers making them highly flexible.

\section{B. DELIVERY FLEXIBILITY}

Table II below shows the responds of the distribution on the delivery flexibility by the respondents.
TABLE II: FREQUENCY DISTRIBUTION OF DELIVERY FLEXIBILITY

\begin{tabular}{|c|c|c|c|c|c|c|c|c|}
\hline Delivery Flexibility & $\mathrm{N}$ & 1 & 2 & 3 & 4 & 5 & Mean & SD \\
\hline Availability of & 3 & 0 & 5 & 16 & 16 & 0 & 3.30 & 0.702 \\
\hline $\begin{array}{l}\text { different modes of } \\
\text { transport in } \\
\text { delivering products }\end{array}$ & 7 & 0 & 13.5 & 43.2 & 43.2 & 0 & & \\
\hline Small delivery order & 3 & 0 & 9 & 13 & 9 & 6 & 3.32 & 1.029 \\
\hline $\begin{array}{l}\text { quantity can be } \\
\text { satisfied }\end{array}$ & 7 & 0 & 24.3 & 35.1 & 24.3 & 16.2 & & \\
\hline Opting for faster & 3 & 0 & 3 & 19 & 12 & 3 & 3.41 & 0.762 \\
\hline $\begin{array}{l}\text { mode of } \\
\text { transportation in case } \\
\text { of urgency }\end{array}$ & 7 & 0 & 8.1 & 51.4 & 32.4 & 8.1 & & \\
\hline
\end{tabular}

High $=5$

The data collected depicts that the availability of different modes of transport in delivering products to the customers were high as depicted by the mean value of 3.3. However, $13.5 \%$ of the respondents representing low were of the view that the other means of delivering products to the customers were not available apart from the normal mode of transporting products. The data collected shows that small delivery order quantity can be satisfied since majority of the respondents indicated for normal, high and very high with the mean value of 3.3. This means that orders that are in small quantities can be easily managed than the larger quantities. Not more attendants needed for small quantities of order because it can be handled satisfactorily. However, few of the respondents were of the view that small delivery order quantity was waste of resources because delivering of products must be in higher volumes.

On the issue of opting for faster mode of transportation in case of urgency, majority of the respondents rated normal as it is indicated on the mean value of the data collected. However, insignificant number of the respondents opted for low. The data indicated that it was highly possible that the management adopted for a faster way of transporting products to their customers in case of urgency. Some of the ways adopted for urgent situations were through airline which though expensive but for the sake of customer loyalty the firms offered these services. Based on the data collected it is clear that the firms attended to the customer's request adequately and promptly because they had different mode of transport for delivery of products, no disappointment and faster way of handling customer order.

\section{INFORMATION SYSTEM FLEXIBILITY}

\section{TABLE III: FREQUENCY DISTRIBUTION OF INFORMATION SYSTEM FLEXIBILITY}

The Table below shows the responds of the distribution on the information system flexibility by the respondents.

\begin{tabular}{lllllllll}
$\begin{array}{l}\text { Information } \\
\begin{array}{l}\text { System } \\
\text { Flexibility }\end{array}\end{array}$ & $N$ & 1 & 2 & 3 & 4 & 5 & Mean & SD \\
\hline
\end{tabular}




\begin{tabular}{|c|c|c|c|c|c|c|c|c|}
\hline $\begin{array}{l}\text { Efficient } \\
\text { information } \\
\text { system } \\
\text { integration with } \\
\text { others }\end{array}$ & $\begin{array}{l}3 \\
7\end{array}$ & $\begin{array}{l}0 \\
0\end{array}$ & $\begin{array}{l}6 \\
16.2\end{array}$ & $\begin{array}{l}24 \\
64.9\end{array}$ & $\begin{array}{l}7 \\
18.9\end{array}$ & $\begin{array}{l}0 \\
0\end{array}$ & 3.03 & 0.600 \\
\hline $\begin{array}{l}\text { Information } \\
\text { technology } \\
\text { hardware and } \\
\text { software system } \\
\text { changes }\end{array}$ & $\begin{array}{l}3 \\
7\end{array}$ & $\begin{array}{l}0 \\
0\end{array}$ & $\begin{array}{l}8 \\
21.6\end{array}$ & $\begin{array}{l}12 \\
32.4\end{array}$ & $\begin{array}{l}14 \\
37.8\end{array}$ & $\begin{array}{l}3 \\
8.1\end{array}$ & 3.14 & 0.855 \\
\hline $\begin{array}{l}\text { Management of } \\
\text { cost and time } \\
\text { for installation } \\
\text { and } \\
\text { maintenance of } \\
\text { information } \\
\text { system } \\
\text { application }\end{array}$ & $\begin{array}{l}3 \\
7\end{array}$ & $\begin{array}{l}0 \\
0\end{array}$ & $\begin{array}{l}8 \\
21.6\end{array}$ & $\begin{array}{l}15 \\
40.5\end{array}$ & $\begin{array}{l}14 \\
37.8\end{array}$ & $\begin{array}{l}0 \\
0\end{array}$ & 2.97 & 0.645 \\
\hline
\end{tabular}

Keys: Very Low $=1$, Low $=2$, Normal $=3$, High $=4$, Very High $=5$

Efficient information system integration with the supply chain network was normally high since $83.8 \%$ of the respondents affirmed it and the mean value of 3.03 also depicts it. In order for information system integration to be efficient, adequate and essential information must be carried out in the industry for operations to go on successfully. On the contrary, few of the respondents indicated low for efficient information system integration.

Globalization has brought a lot of changes in the company's information technology hardware and software systems. Due to hacking of the systems software, it has been designed in such a way that penetration into the systems becomes difficult. Majority of the respondents were in agreement as the mean of 3.14 shows while small number of respondents disagreed.

Lastly, management of cost and time for installation and maintenance of information system applications is high as majority of the respondents affirmed it and the mean value (3.24) of the data also affirmed it. However, minority of the respondents rated low. This means the cost and time involved in installing and maintaining information technology must be carefully managed.

Finally, the data collected clearly illustrates that it is essential for the firms to efficiently integrate their system with others and quickly responding to information feedback.

\section{ASSESSING SUPPLY CHAIN FLEXIBILITY DRIVERS}

\section{TABLE IV: FREQUENCY DISTRIBUTION OF SUPPLY CHAIN FLEXIBILITY DRIVERS}

The Table below shows the responds of the distribution on the supply chain flexibility drivers by the respondents.

\begin{tabular}{lllllll}
\hline $\begin{array}{l}\text { Flexibility } \\
\text { Drivers }\end{array}$ & N & 1 & 2 & 3 & Mean & SD \\
\end{tabular}

\begin{tabular}{|c|c|c|c|c|c|c|}
\hline $\begin{array}{l}\text { Product life cycle } \\
\text { for majority of } \\
\text { products }\end{array}$ & 37 & 0 & 59.5 & 40.5 & 2.41 & 0.498 \\
\hline \multirow[t]{2}{*}{ Product variety } & 37 & 2 & 22 & 13 & 2.30 & 0.571 \\
\hline & & 5.4 & 59.5 & 35.1 & & \\
\hline $\begin{array}{l}\text { Customers } \\
\text { requirement }\end{array}$ & 37 & 4 & 20 & 13 & 2.24 & 0.641 \\
\hline disparity & & 10.8 & 54.1 & 35.1 & & \\
\hline
\end{tabular}

Keys: Very Low $=1$, Low $=2$, Normal $=3$, High $=4$, Very High $=5$

In the data collected, it is clear that the product life cycle for majority of the firm's products is medium as indicated by the mean value of 2.41. However, almost half of the respondents rated long. This means that the period product stays in the market before its disappearance or time frame before product enters market is neither short nor long. Normally, products should not stay for long time during production process before it goes out to the market and also its disappearance from the market.

On the product variety, the respondents indicated as the data showed by the mean value to be medium. This shows that the firms produced different sizes of products though not on the larger scale since product variety is the number of variety of products produced at a particular time or season by the firms. Since product variety is medium it is economical for the firm's operation because large product variety makes delivering often expensive.

The study shows that the respondents rated medium on customer requirement disparity as shown by the mean value of 2.30. From the table, it could be deduced that the customer requirement disparity is medium and since the services required by each customer differs, it is essential to employ different kinds of transportation and delivering devices to reduce cost and maximize profit. Based on the data collected on the supply chain flexibility drivers, it can be concluded that the length of product life cycle is medium. The product variety is medium which is economical for the firm's operation to be smoothly carried out because large product variety makes delivering often expensive. Lastly, customer requirement disparity is medium and it is good for the firms since services required by each customer differs, it is essential to employ different kinds of transportation and delivering devices to reduce cost. 
E. RELATIONSHIP BETWEEN SUPPLY CHAIN DRIVERS AND DIMENSIONS

TABLE V: RELATIONSHIP BETWEEN SUPPLY CHAIN DRIVERS AND DIMENSIONS

\section{CORRELATIONS}

\section{(1)}

(2)

(3)

(4)

(5)

(6)

Product life cycle for majority of 1

products (1)

Efficient information system

integration with others (2)

Adequate flow of material for

manufacturing process (3)

Availability of diff modes of transport (4)

$.043 \quad .376^{*} \quad .428^{* *} \quad 1$

Cordial relationship with suppliers $\quad-.173$

(5)

$.474^{* *} \quad .207$

$.551^{* *}$

1

Existing product modification (6) $\quad-.270 \quad .06$

.064

$.008 \quad-.338^{*}$

.102

1

${ }^{*}$ Correlation is significant at the 0.05 level (2-tailed)

**Correlation is significant at the 0.01 level (2tailed) 


\section{INFORMATION SYSTEM FLEXIBILITY}

Table $\mathrm{V}$ was used to find the relationship between supply chain drivers and dimensions in the study area. It shows that there was moderate relationship between efficient information system integration with others and cordial relationship with suppliers $(\mathrm{r}=0.474)$. This indicates the prediction between efficient information system integration with others and cordial relationship with suppliers was $47.4 \%$.

Again, table was used to find the relationship between cordial relationship with suppliers and adequate flow of material for manufacturing process. It was also shows that there was weak relationship between cordial relationship with suppliers and adequate flow of material for manufacturing process $(\mathrm{r}=$ 0.207). This indicates the prediction between cordial relationship with suppliers and adequate flow of material for manufacturing process was $20.7 \%$ (detail are shown in table $\mathrm{V})$.

\section{SUMMARY, CONCLUSION AND RECOMMENDATIONS}

\section{A. PRODUCT FLEXIBILITY}

The findings indicated that existing products must be modified in order to attract customers. The characteristics that distinguish it from one another are quality, product designs, packaging, and portability. However, few respondents opposed to the idea. The majority agreed that the setup cost and time for the machines should be managed effectively and efficiently to avoid breakdowns in order to decrease setup cost and optimized profit. It was clearly indicated that firms have alternative route to produce products and ability of the team to produce different designs that suite the customer expectations and interest such as product sizes, pricing and quantity among others.

\section{B. DELIVERY FLEXIBILITY}

The study conducted clearly indicated that the firms attended to the customer's request adequately and promptly since they have different mode of transport for delivery of product. Also, it is easier to deliver small quantity since small quantities can be easily managed than the larger quantities. The majority of the respondents illustrates that their firms attended to its customer needs quickly without delaying. Finally, the firms do not disappoint its customers on the delivery time since they are aware of the consequences.
The data collected clearly illustrates that it is essential for the firms to efficiently integrate their system with others and quickly responding to information feedback. Vibrant supply chain information systems enable quality growth of products and services, information services and e-business links, reduction of inventory, customer service improvement. Finally, proper installation of the systems and periodic routine maintenance must be strictly adhered to in order to minimize the overhead cost and maximize profit.

\section{SUPPLY CHAIN FLEXIBILITY DRIVERS}

This summarizes the findings of the study on the supply chain flexibility drivers. Based on the data collected on the supply chain flexibility drivers, it can be concluded that the length of product life cycle is medium meaning the period product stays in the market before its disappearance or time frame before product enters the market is neither short nor long. The product variety is medium, which is economical for the firm's operation to be smoothly carried out because large product variety makes delivering often expensive. Customer requirement disparity is medium and it is good for the firms since services required by each customer differs, it is essential to employ different kinds of transportation and delivering devices to reduce cost.

\section{E. CORRELATION ANALYSIS}

It was observed that there was moderate relationship between efficient information system integration with others and cordial relationship with suppliers $(\mathrm{r}=0.474)$. Also, it showed that there was a weak relationship between cordial relationship with suppliers and adequate flow of material for manufacturing process $(r=0.207)$.

\section{CONCLUSION}

Bottling water industries experiencing inevitable environmental uncertainties through technological transformations and adjustments, global competition, innovation, rise in customer demands and expectations. The expansion of market and other factors has necessitated the firms to adopt supply chain flexibility in their operations to cope with the uncertainties in the business environment so that they would able to meet the fluctuations in demand. In evaluating the supply chain flexibility performance in the bottling water industries in the Kumasi Metropolis, the study found out that firms modifies its products, manage its setup 
cost effectively and having different ways of producing products even during the massive power outrages they were able to design products. Moreover, the delivery flexibility of the firms is high since they attended to the customer's request adequately and promptly because of different modes of transporting products to customers and logistics flexibility is also high in the sense that there is an adequate flow of materials for manufacturing and delivery. The information system flexibility on the average is good since the firms integrate information efficiently and respond quickly to feedbacks. Adoption of the flexibility strategies helps companies to increase their market share and growth and stay in competitive business. On the other hand, the study found out that the product life cycle is medium signifying that product does not stay long time in the market. The product variety is medium meaning different sizes of products are produced at the same time. Lastly, customer requirement disparity is medium which means there should be variations in the customer service level. Order stability is high indicating that firms managed customer orders adequately. Different materials are used in production making component commonality medium. Process similarity is high which shows that different products pass through similar machine reducing cost. Furthermore, there is low supply uncertainty making competition in acquiring raw materials healthy and supply chain performance is high in the firms which make the level of customer satisfaction boost up. Customers perceived firm's products high and able to answer customer's queries timely in order to increase average sales growth.

Based on the findings of the study, the following recommendations have been enumerated to help improve the supply chain flexibility performance of the bottling water industry: The study recommends that there should be product modification in order to attract and suite customers. The cordiality between the firms and their suppliers should be maintained to avoid shortage of raw materials. There should be an effective communication in the firm to increase production. The firms should make differentiation of products priority to be in competitive business. Moreover, the study recommends that firms should have appropriate modes of transportation to distribute products to the customers to avoid stock-out and to satisfy customer's orders by responding to urgent request. The stakeholders in effective and efficient supply chain management practices on the supply chain flexibility dimensions and drivers should strengthen their internal guidelines, strategies and systems for the collection and analysis of performance and the development of capacity building. This will empower great ideas out of dealings in the bottling water industry. Finally, it is recommended that further research should be conducted to investigate the supply chain flexibility performance in other industries such as food and canary processing, petroleum, plastic products, and others. 


\section{REFERENCES}

[1] Fawcett, E. S., Ellram, A. L. \& Ogden, A. J. Supply Chain Management: from vision to implementation. New Jersey (NJ): Pearson Education Inc. 2007.

[2] Chopra, Sunil, and Peter Meindl. "Supply chain management. Strategy, planning \& operation." In Das summa summarum des management, pp. 265-275. Gabler, 2007.

[3] Zhang, Qingyu, Mark A. Vonderembse, and Jeen-Su Lim. "Value chain flexibility: a dichotomy of competence and capability." International journal of production research 40, no. 3 (2002): 561-583

[4] Upton, David M. "The management of manufacturing flexibility." California management review 36, no. 2 (1994): 72-89.

[5] Yi, Candace Y., E. W. T. Ngai, and K. L. Moon. "Supply chain flexibility in an uncertain environment: exploratory findings from five case studies." Supply Chain Management: An International Journal 16, no. 4 (2011): 271-283.

[6] Vickery, S. N., Calantone, R. and Droge, C. "Supply chain flexibility: an empirical study", The Journal of Supply Chain Management 1999.

[7] Aissa Fantazy, Kamel, Vinod Kumar, and Uma Kumar. "An empirical study of the relationships among strategy, flexibility, and performance in the supply chain context." Supply Chain Management: An International Journal 14, no. 3 (2009): 177-188.

[8] Sethi, Andrea Krasa, and Suresh Pal Sethi. "Flexibility in manufacturing: a survey." International journal of flexible manufacturing systems 2, no. 4 (1990): 289-328.

[9] Upton, David M. "Process range in manufacturing: an empirical study of flexibility." Management Science 43, no. 8 (1997): 1079-

[10] Lee, Hau L. "The triple-A supply chain." Harvard business review 82, no. 10 (2004): 102-113.

[11] Martínez Sánchez, Angel, and Manuela Pérez Pérez. "Supply chain flexibility and firm performance: a conceptual model and empirical study in the automotive industry." International Journal of Operations \& Production Management 25, no. 7 (2005): 681-700.

[12] Duclos, Leslie K., Robert J. Vokurka, and Rhonda R. Lummus. "A conceptual model of supply chain flexibility." Industrial Management \& Data Systems 103, no. 6 (2003): 446-456

[13] Fine, Charles H., and Robert M. Freund. "Optimal investment in product-flexible manufacturing capacity." Management Science 36, no. 4 (1990): 449-466.
[14] Fantazy, K.A., Kumar, V. and Kumar, U. An empirical study of the relationships among strategy, flexibility, and performance in the supply chain context. Supply Chain Management: An International Journal 2009.

[15] D'Souza, Derrick E., and Fredrik P. Williams. "Toward a taxonomy of manufacturing flexibility dimensions." Journal of operations management 18, no. 5 (2000): 577-593.

[16] Suarez, Ferando F., Michael A. Cusumano, and Charles H. Fine. "An empirical study of flexibility in manufacturing." MIT Sloan Management Review 37, no. 1 (1995): 25.

[17] Archer, Norman P., Vinod Kumar, Kamel A. Fantazy, Uma Kumar, and Todd A. Boyle. "Implementation and management framework for supply chain flexibility." Journal of Enterprise Information Management (2006).

[18] Cooper, D. R. and Schindler, P. S. Business Research Methods (Eight edn.; New York: McGraw-Hill) 2003.

\section{BIOGRAPHY}

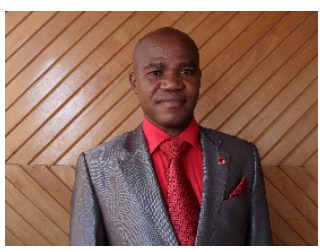

Evans Kyeremeh holds Master of Philosophy in Logistics and Supply Chain Management, Master of Business Administration in Logistics and Supply Chain Management and Bachelor of Science (Psychology). He is a Lecturer at the Department of Marketing, Procurement and Supply Chain Management, School of Business, University of Education, Winneba, Ghana.

His area of research includes Supply Chain Management, Logistics, Warehousing and Material Handling and Corruption in Public Procurement.

He has authored a number of articles in the subject area. 